\title{
Delayed Ventricular Septal Rupture Following Blunt Chest Trauma
}

\author{
Na Young Kim, $\mathrm{MD}^{1}$, Tae Jung Kwon, $\mathrm{MD}^{1}$, Jeong Rang Park, $\mathrm{MD}^{1}$, Ho Cheol Choi, $\mathrm{MD}^{2}$, \\ Yun Hong Cheon, $\mathrm{MD}^{1}$, Min Kyu Kang, $\mathrm{MD}^{1}$, Seok-Jae Hwang, $\mathrm{MD}^{1}$, Yongwhi Park, $\mathrm{MD}^{1}$, \\ Young-Hoon Jeong, $\mathrm{MD}^{1}$, Choong Hwan Kwak, $\mathrm{MD}^{1}$, and Jin-Yong Hwang, $\mathrm{MD}^{1}$ \\ ${ }^{1}$ Departments of Internal Medicine and ${ }^{2}$ Radiology, Gyeongsang National University Hospital, Jinju, Korea
}

\begin{abstract}
Cardiac injury is a common but occasionally serious complication of blunt chest trauma. A ventricular septal rupture (VSR) is a rare complication and is variable in its presentation, temporal course and severity. Here, we report a rare case of 75-yearold man who developed delayed VSR following blunt chest trauma. (Korean Circ J 2011;41:625-628)
\end{abstract}

KEY WORDS: Ventricular septal rupture; Thoracic injuries.

\section{Introduction}

Cardiac injury is a common complication of blunt chest trauma. The common injuries include cardiac contusion, valvular damage and aortic insufficiency. ${ }^{1)}$ A ventricular septal rupture (VSR) is a rare complication following non-penetrating chest trauma. VSR may be delayed for several hours to several days after trauma and its clinical presentation is varying from immediate death to complete spontaneous closure. Therefore, closed observation is essential for the management of these patients. We report a rare case of delayed VSR with complete atrioventricular (AV) block following blunt chest trauma.

\section{Case}

A 75-year-old man was admitted to the regional hospital following a traffic accident. His motorized wheelchair turned over and he suffered bruised left ribs. Before the accident,

\section{Received: December 8, 2010}

Revision Received: January 4, 2011

Accepted: January 17, 2011

Correspondence: Jeong Rang Park, MD, Department of Internal Medicine, Gyeongsang National University Hospital, 90 Chiram-dong, Jinju 660702 , Korea

Tel: 82-55-750-8068, Fax: 82-55-755-9078

E-mail: parkjrang@gmail.com

- The authors have no financial conflicts of interest.

$\circledast$ This is an Open Access article distributed under the terms of the Creative Commons Attribution Non-Commercial License (http://creativecommons.org/licenses/by-nc/3.0) which permits unrestricted non-commercial use, distribution, and reproduction in any medium, provided the original work is properly cited. he had been treated for essential hypertension. He underwent below-knee amputation of his left leg due to a traffic accident 40 years ago. He was initially diagnosed with fractures of the left 3rd to 5th ribs and left scapula. On the second day after hospitalization, he had respiratory distress and was consequently transferred to Gyeongsang National University Hospital. His blood pressure was 70/40 mm Hg; heart rate, 40 beats $/ \mathrm{min}$; respiration rate, $30 / \mathrm{min}$; and temperature, $36.9^{\circ} \mathrm{C}$. On physical examination, cardiac murmur was not heard. Rales and wheezing sound were heard on both lung fields. Initial chest radiograph showed infiltration on both upper lung fields. The initial electrocardiogram (ECG) showed a complete AV block (Fig. 1). Transthoracic echocardiogram revealed normal ventricular function and mild tricuspid regurgitation with moderately elevated pulmonary hypertension. $\mathrm{Cr}$ eatine kinase (CK) isoenzyme levels were raised (CK 2,389 $\mathrm{U} / \mathrm{L}$, normal range 0-170 U/L; CK-MB $21.3 \mathrm{ng} / \mathrm{mL}$, normal range $0.6-6.3 \mathrm{ng} / \mathrm{mL}$ ) and troponin I level was $0.3 \mathrm{ng} / \mathrm{mL}$ (normal range $0.0-0.04 \mathrm{ng} / \mathrm{mL}$ ). After fluid replacement, his blood pressure was restored to $140 / 90 \mathrm{~mm} \mathrm{Hg}$. He received treatment for acute lung injury. On the 11th day after the accident, he presented with aggravated dyspnea and tachypnea. A new grade $4 / 6$ holosystolic murmur could be heard at the left sternal border. Findings on ECG were changed to normal sinus rhythm and diffuse $\mathrm{T}$ inversion on inferior and precordial leads (Fig. 2). CK-MB was $6.7 \mathrm{ng} / \mathrm{mL}$ and troponin I was raised to a level of $4.31 \mathrm{ng} / \mathrm{mL}$. Transthoracic echocardiogram revealed septal akinesia and ventricular septal defect (VSD) near the apex (Fig. 3), but the patient had no complaint of chest pain. On coronary CT angiography, significant stenosis was not seen and VSD was observed (Fig. 4). Cardiac magnetic reson- 
ance imaging (MRI) to rule out myocardial infarction revealed apical septal VSD with normal perfusion of the interventricular septal wall. There were no delayed enhanced le- sions suggesting myocardial fibrosis (Fig. 5). The Qp/Qs measured by shunt scan was 1.52 . After medication with diuretics, dyspnea and pulmonary edema were completely improved. He

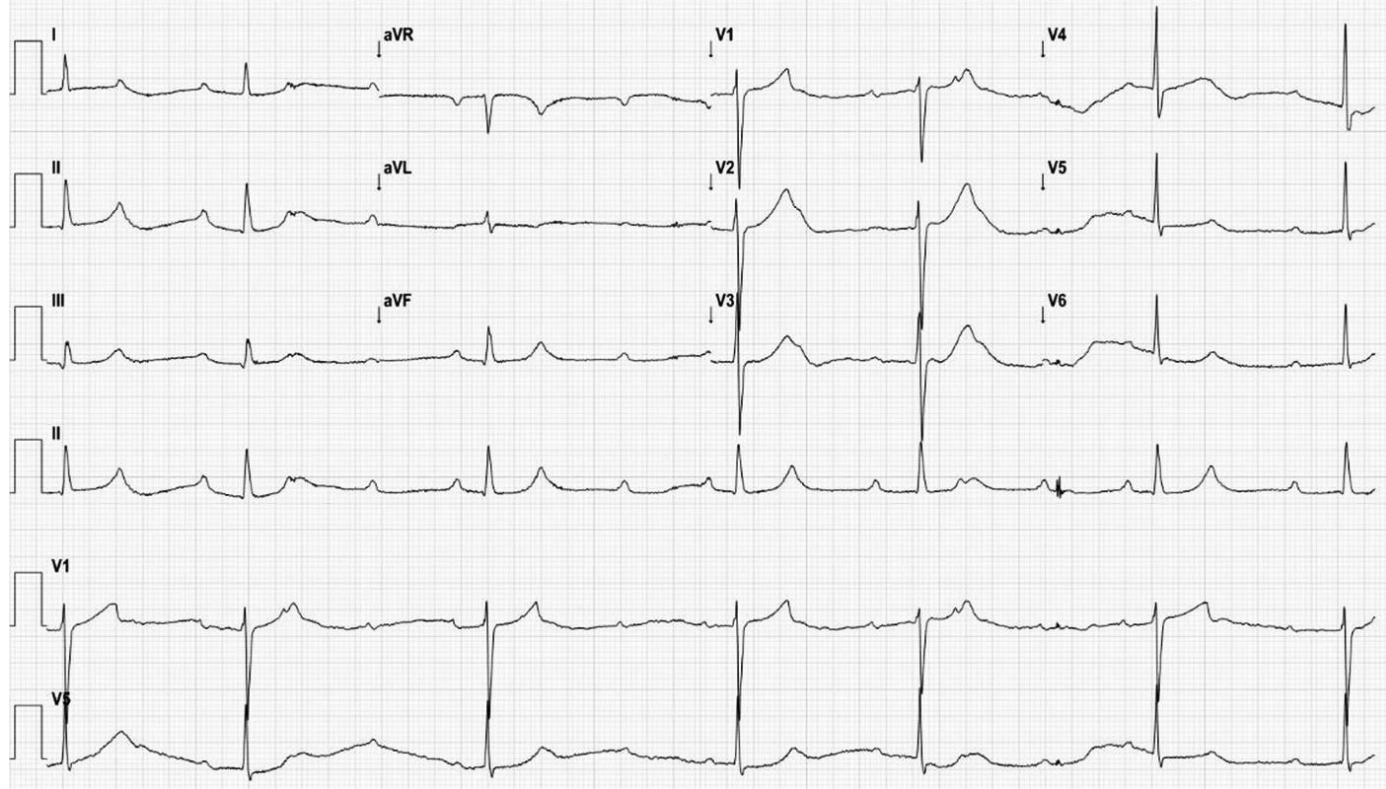

Fig. 1. Twelve-lead electrocardiogram on admission shows complete atrioventricular block.

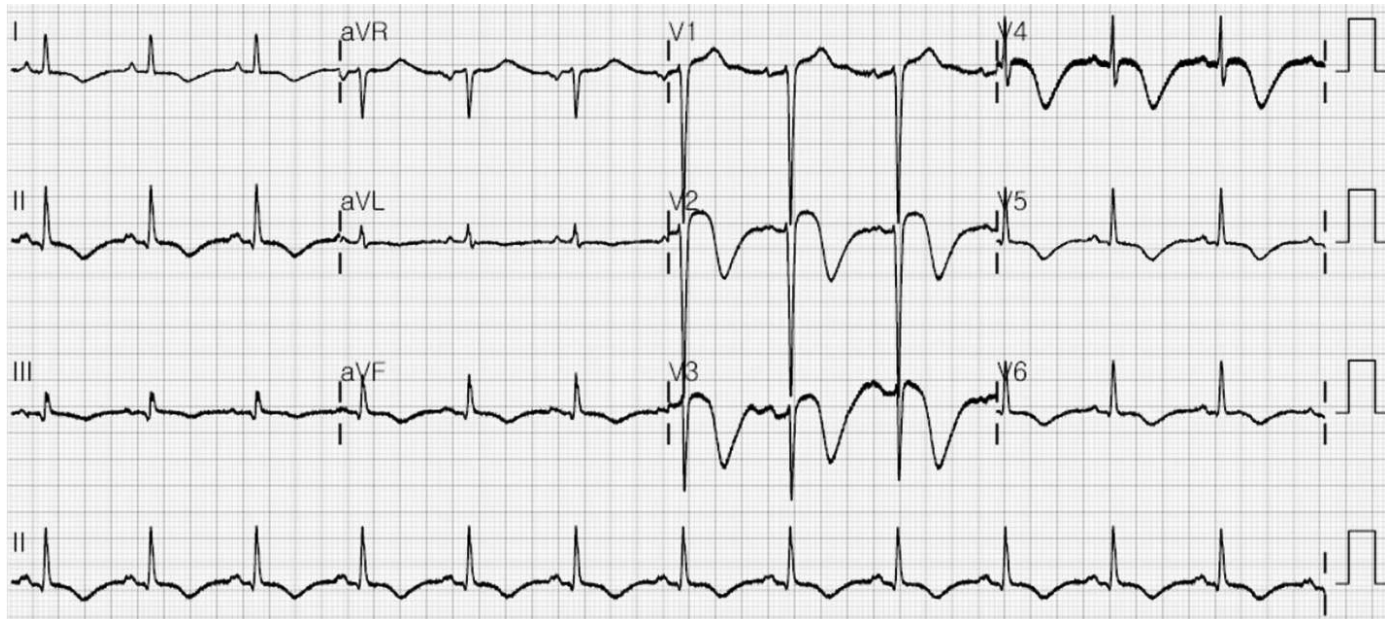

Fig. 2. Electrocardiogram on the 11th day after the accident shows normal sinus rhythm with diffuse T wave inversion on inferior and precordial leads.
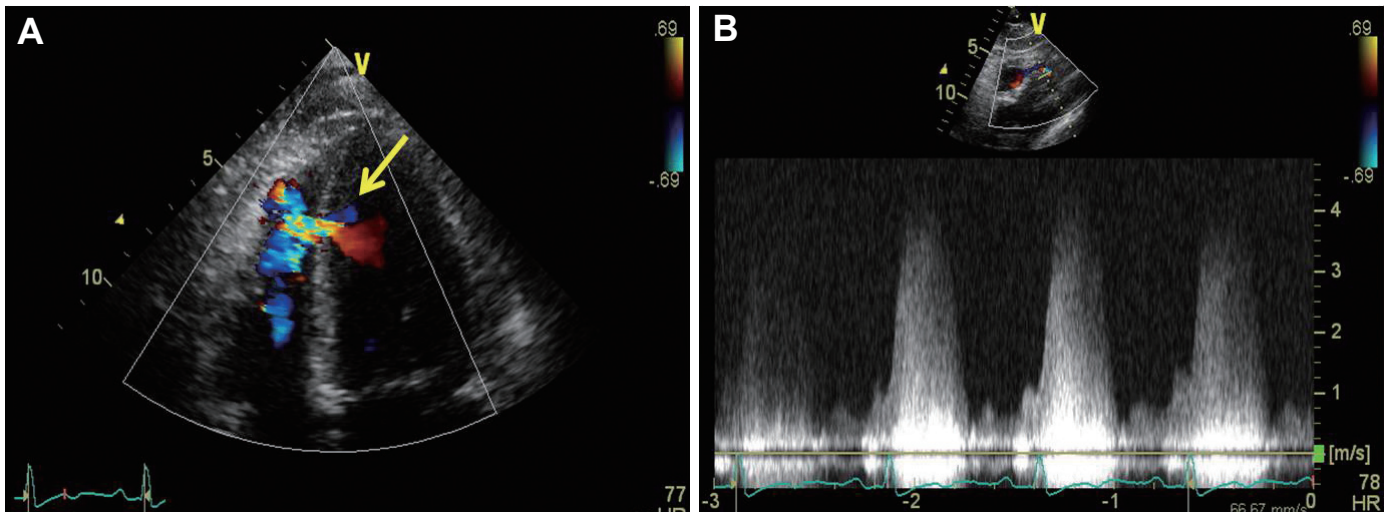

Fig. 3. Transthoracic echocardiography. A: apical four chamber view: ventricular septal defect (arrow) is seen near the apex. B: subcostal view: continuous wave Doppler shows left-to-right shunt pattern. 

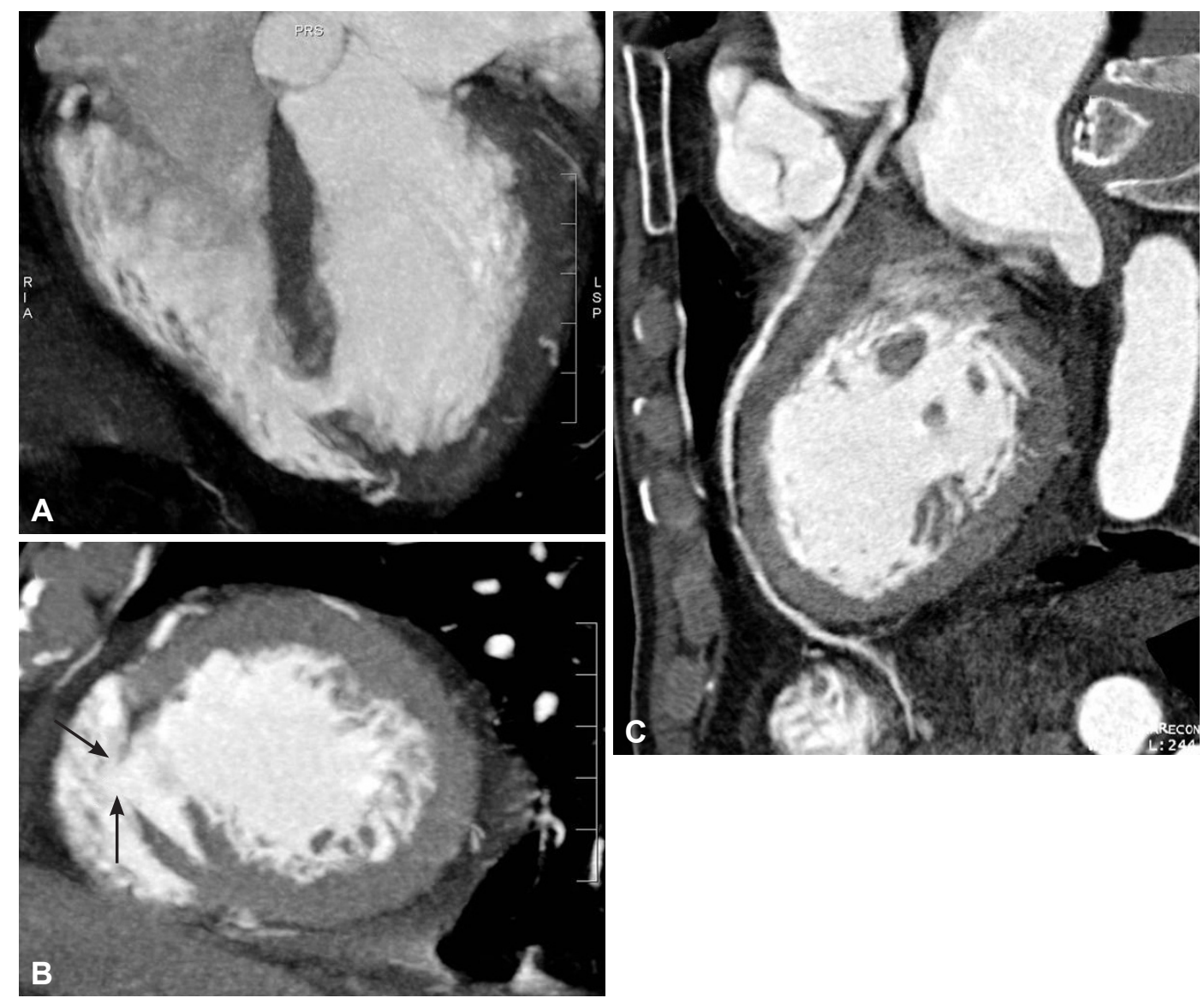

Fig. 4. Cardiac computed tomography. Ventricular septal rupture and $0.7 \mathrm{~cm}$ size shunt (inter-arrow site) is identified at apical four chamber view (A) and short axis view (B). There is no significant stenosis of the left anterior descending artery (C).

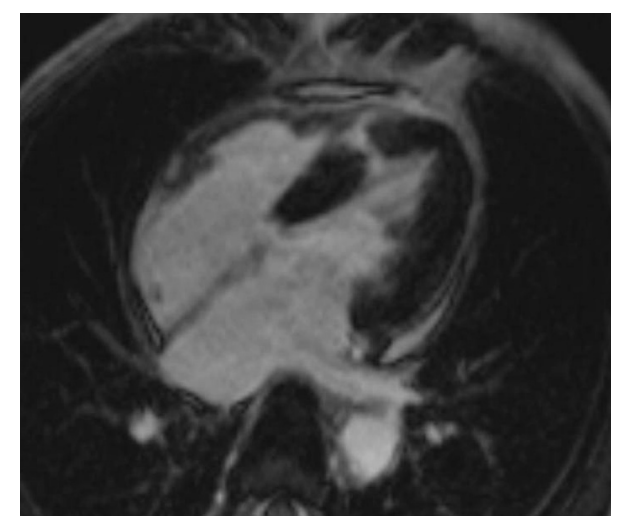

Fig. 5. Cardiac magnetic resonance imaging revealed apical ventricular septal defect without delayed enhancement.

was discharged without surgical correction because he did not want an operation and $\mathrm{Qp} / \mathrm{Qs}$ was less than 2. Unfortunately, he died due to uncontrolled pneumonia after 1 month.

\section{Discussion}

Myocardial contusion is the most frequent cardiac injury following blunt chest trauma and occurs in 16-76\% of patients involved in motor vehicle accidents. ${ }^{2)} \mathrm{A}$ VSR is a rare complication following blunt chest trauma. ${ }^{3}$
The first postulated mechanism of VSR is acute compression of the heart with a resultant sudden rise in intracardiac pressure during the end of diastole or isovolumetric systole ${ }^{3)}$ and the second postulated mechanism is that myocardial injury causes a microvascular disruption leading to infarction and liquefaction of the septum.4) The contused myocardium can become necrotic and subsequently perforate. Therefore, VSR may occur several hours to months after blunt trauma." Traumatic VSR is usually located near the apex, in the muscular portion of the septum, in contrast to a congenital VSD that occurs adjacent to the membranous septum. Cleland et al. ${ }^{6}$ reported that presence of fibrosis adjacent to the ruptured myocardium is helpful for differentiating traumatic VSR from a congenital VSD. Jun et al. ${ }^{7)}$ showed that cardiac MRI demonstrated delayed enhancement consistent with fibrotic scars in the patient with VSR after blunt trauma. In our patient, cardiac MRI did not show delayed enhancement and we confirmed normal coronary perfusion. We thought that presence or absence of fibrosis and the amount of fibrosis may differ among the various mechanisms of VSR.

Echocardiography is the method of choice for diagnosis and guiding the management of VSR. However, echocardiography is sometimes difficult to give enough information. Cardiac CT and MRI can help to differentiate the causes of VSD and 
confirm the presence of combined coronary artery disease.

In traumatic VSR, conservative approach has been recommended for asymptomatic patients with small VSD when the ratio of pulmonary to systemic flows is clearly less than $2: 1$ because spontaneous closure is possible. ${ }^{8)}$ Surgical or percutaneous closure is necessary in patients with hemodynamic instability and a large defect.

Our patient presented with complete AV block at the time of admission. Arrhythmia as a complication of blunt chest trauma had been reported to occur in up to $70 \%$ of patients within the first 3 days of hospitalization. ${ }^{9)}$ High degree AV blo$\mathrm{ck}$ is an unusual complication after blunt chest trauma. The suggested mechanisms are a tear in the conduction system and a contusion or hemorrhage near the AV node. ${ }^{10)}$ In this case, the development of VSR and conversion to sinus rhythm occurred simultaneously. Therefore, we believed that the main mechanism of AV block in our patient may be stretching of the conduction system as a result of edema of the interventricular septum. VSR may lead to relieving of tension and recovering to sinus rhythm.

There were a few cases of VSR following non-penetrating chest trauma in Korea. ${ }^{1112)}$ However, to our knowledge there has not been a case reported of delayed presentation of traumatic VSR with AV block. Here, we report a case of delayed VSR and high degree AV block following blunt chest trauma. VSR can occur several days later and VSR should be considered in cases of chest trauma with increased troponin level, new heart murmur, ECG change or hemodynamic instability. Therefore, watchful physical examination and hemodynamic monitoring are required for patients with chest trauma. Serial echocardiographic monitoring should be performed, es- pecially if cardiac contusion is expected.

\section{REFERENCES}

1) Hamdan-Challe M, Godin M, Bouchart F, Doguet F. Isolated ventricular septal rupture secondary to blunt trauma. Interact Cardiovasc Thorac Surg 2010;11:667-9.

2) Fang BR, Li CT. Acute myocardial infarction following blunt chest trauma. Eur Heart J 1994;15:705-7.

3) Blasco PB, Comas JG, del Alcazar Munoz R. Spontaneous improvement of a haemodynamically significant ventricular septal defect produced by blunt chest trauma in a child. Cardiol Young 2009;19:109-10.

4) Genoni M, Jenni R, Turina M. Traumatic ventricular septal defect. Heart 1997;78:316-8.

5) Dehghani P, Ibrahim R, Collins N, Latter D, Cheema AN, Chisholm RJ. Post-traumatic ventricular septal defects: review of the literature and a novel technique for percutaneous closure. J Invasive Cardiol 2009;21:483-7.

6) Cleland WP, Ellman P, Goodwin J, Hollman A. Repair of ventricular septal defect following indirect trauma. Br J Dis Chest 1961;55:17-22.

7) Jun SL, Chanani NK, Moore P, Higgins CB. Magnetic resonance imaging of a posttraumatic myocardial infarction and ventricular septal defect with a closure device in place. Circulation 2007;115:e13-5.

8) Pesenti-Rossi D, Godart F, Dubar A, Rey C. Transcatheter closure of traumatic ventricular septal defect: an alternative to surgery. Chest 2003;123:2144-5.

9) Sakka SG, Huettemann E, Giebe W, Reinhart K. Late cardiac arrhythmias after blunt chest trauma. Intensive Care Med 2000;26: 792-5.

10) Helling TS, Duke P, Beggs CW, Crouse LJ. A prospective evaluation of 68 patients suffering blunt chest trauma for evidence of cardiac injury. J Trauma 1989;29:961-6.

11) Yun HJ, Jin SW, Ahn YY, et al. A case of isolated ventricular septal rupture following non-penetrating chest trauma. J Korean Soc Echocardiogr 2001;9:157-60.

12) Lee WS, Lee IK, Kim KS, Kim YN, Kim KB. A case of traumatic ventricular septal defect secondary to nonpenetrating chest trauma. Korean Circ J 1987; 17:381-7. 